\title{
La utopia com a tragèdia moderna dels subjectes post-utòpics
}

\section{Enric Prats *}

\section{Resum}

El sentit comú situaria els termes utopia i tragèdia en pols semàntics oposats. En el terreny del pensament pedagògic, des de fa dos segles, l'educació s'hauria situat més aviat en el primer d'aquests extrems, llevat d'algunes destacades excepcions. Molt probablement l'envestida moderna, amb idees tan seductores com les de progrés i emancipació, hauria conduït aquelles pedagogies per territoris adobats per l'optimisme i l'expectativa de mons millors, sempre del bracet de l'educació com a eina per assolir-los. També molt probablement, en canvi, l'enfonsada de les utopies totalitzants durant el segle xx hauria estat el símptoma d'un mal endèmic encara per esbrinar. La tragèdia de la finitud, amagada amb la modernitat, quedaria al descobert amb aquell aclofament, una situació que els post-modernismes haurien volgut superar amb la negació de la història i, també, del futur. El subjecte post-utòpic emergeix com algú que no espera més que un futur programat que no desperta cap mena de passió, una veritable tragèdia per a la pedagogia.

\section{Paraules clau}

Postmodernitat, utopia, tragèdia, pedagogia

Recepció original: 30 de setembre de 2020

Acceptació: 19 de novembre de 2020

Publicació: 16 de desembre de 2020

\section{La utopia com advertiment tràgic ${ }^{1}$}

Potser resulti una mica temerari posar en una mateixa frase paraules aparentment tan antagòniques com a utopia i tragèdia. Una interpretació simple podria admetre que molt probablement la vessant negativa de la utopia, sigui en clau distòpica, heterotòpica o fins i tot ucrònica, estaria en sintonia amb una determinada pulsió tràgica. Però cal aportar més elements per afermar aquest hipotètic rerefons tràgic que sosté tota utopia; també les utopies d'un món feliç.

Pot quedar fora de tot dubte que la distopia sorgeix de la desesperança tràgica, hereva encara de la idea de progrés, un aspecte que per a la distopia significa un esglaó més cap a la catàstrofe. La robotització, per exemple, o la invasió d'éssers extraterrestres dotats d'una intel-ligència superior, són dues cares de la mateixa moneda: el reconeixement tràgic de les limitacions humanes. En tots dos casos, s'inverteix l'equació parasitària que hauria dominat el discurs de la modernitat, segons la qual l'home es legitimava com a espoliador del planeta, un paràsit de la resta d'espècies animals i vegetals, amb les quals estaria autoritzat a perpetuar una relació d'amo i servent. En els malsons distòpics, els

$\left(^{*}\right)$ Professor del Departament Teoria i Història de l'Educació de la Universitat de Barcelona. Director de la col·lecció Pedagogies UB que promou Edicions de la Universitat de Barcelona. Membre del GREPPS (Grup de Recerca en Pensament Pedagògic i Social). Entre altres títols ha publicat: L'educació qüestió d'estat: una mirada a Europa (2013), Teorizando en educación: entre erudición, poesía y opinionitis (2015), Aprendre de lletres: literatura i pedagogia, vides paral.leles (2016) i L'escola importa: notes per repensar l'educació (2019). Adreça electrònica: enricprats@ub.edu

(1) Aquest text és una versió adaptada d'una investigació duta a terme en el marc del Màster de Teoria de la Literatura i Literatura Comparada, de la Universitat de Barcelona, dirigida pel prof. Àlex Matas Pons. 
marcians vindrien a dominar el planeta i sotmetre l'ésser humà, que passaria a exercir de criat, la mateixa fórmula utilitzada amb els robots, que abandonarien la seva condició de serfs per arribar a dominar el món. Aquesta és la hipòtesi que Samuel Butler desvetllava en Erewhon (1872), un lloc en algun Iloc (com amaga l'anagrama del seu títol), on residia una civilització que havia superat la dictadura de les màquines, no sense abans patir una guerra civil entre els maquinistes i els antimaquinistes o, en termes més moderns, entre tecnofílics i tecnofòbics: el seu argument principal era que els humans no perdessin la condició de paràsits del món conegut a favor de la incipient mecanització.

Fins a principis del segle $\mathrm{xx}$, la utopia hauria servit d'advertiment i de reclam per recuperar la raó o el sentit, com ja postulava More, i per desemmascarar les il.lusions del fals progressisme basat en la industrialització salvatge i l'explotació il-limitada del planeta, un diagnòstic que obria les portes de la distopia (Trousson, 1979, p. 15). Vindria a ser, dit en altres paraules, una versió moderna de la tragèdia que sorgeix de reconèixer les limitacions del cos amb relació a l'ànima, o de la raó amb les passions, que des de Plató i els estoics recorre el pensament antic: «una ànima que moralment ha d'intentar deslligar-se, evadir-se, abandonar les tenebres de la gruta corporal», que arribarà a legitimar el suïcidi en Sèneca, ja que permet franquejar «la presó del cos» (Serés, 2019, p. 39), un suïcidi que no és més que la metàfora distòpica de la societat actual, que es podria anar relatant enllaçant els grans esdeveniments de la història recent d'Europa: les dues grans guerres mundials, l'Holocaust, el Mur, la crisi dels Balcans, Idomeni. Aquests paral-lelismes no significaran precisament una coincidència d'enfocaments o paradigmes.

\section{Esperança i responsabilitat}

La fascinació i el fanatisme que desperten la il.lusió d'imaginar i controlar el desenvolupament de futurs possibles, acompanyada aquesta il.lusió del principi dialèctic d'esperança, anunciat per Ernst Bloch i destronat per Hans Jonas i el seu principi liberal de responsabilitat, s'ubiquen en una concepció lineal de la història, sempre sota la promesa d'horitzons millors que han de venir, encara que poques vegades quedin descrits els passos o processos per assolir-los, i les penes que caldria esmerçar-hi.

Semblen transmetre la sensació, els utòpics, que els paradisos descrits han emergit sense una història anterior, de què es desconeixen fases o episodis pretèrits i sempre contraris a l'escenari assolit. Paradoxalment, no existiria la història o, en el millor dels casos, és preferible oblidar-la o reemplaçar-la per la memòria, la codificació i catalogació de la qual es fa urgent en qualitat de registre de la crueltat. Aquesta seria l'estratègia d'incloure el diari de Henríquez, a Non luogo a procedere (2015), de Claudio Magris, o l'ús de fotografies i la llista en ordre alfabètic dels més de 9.000 jueus deportats o exterminats, que Daša Drndic intercala, al Ilarg de 80 pàgines, en Sonnenschein (2007), la seva novel.la amb el rerefons de la Risiera de San Sabba de Trieste, camp de concentració i d'extermini nazi situat als afores de la ciutat, perquè «darrere de cada nom hi ha una història».

Aquest registre vindrà a funcionar com a criteri de versemblança i veracitat en una societat de postveritats, on l'excés de detalls serà important per arribar a desemmascarar personatges com Enric Marco, la no-víctima dels horrors nazis, i víctima alhora de la seva mateixa possessió de veritats post-utòpiques: «Cosa succede quando la verità viene dalla bocca di un bugliardo, di un impostore che racconta cose realmente accadute?» (Magris, 2007). 
El final de la història, ara ho sabem, no es va produir el 1989. Es va presentar, segons Magris, a manera de síntesi entre emancipació i regressió, instal-lant-se un «totalitarisme suau» de "gelatinoses ideologies febles» hàbilment promocionades i publicitades pels mitjans de comunicació (Magris, 1996, p. 10). Efectivament, entre finals de la dècada de 1970, en els límits definits per la publicació de La condició postmoderna (1979) de Lyotard, i l'11 de setembre de 2001, es va obrir un «temps encavalcat», un Sattelzeit, en paraules de Koselleck, segons Enzo Traverso, un temps de pas: «Els punts extrems d'aquest Sattelzeit són la utopia i la memòria», com a «marc polític i epistèmic del nou segle obert pel final de la Guerra Freda» (Traverso, 2016, p. 27).

Tradicionalment, les crisis i revolucions havien significat una fàbrica d'utopies. Les revolucions de vellut, fins i tot les revolucions de la primavera àrab, haurien frustrat, segons el parer de Traverso, «qualsevol somni anterior i van paralitzar la producció cultural; en comptes de projectar-se al futur, aquestes revolucions van crear societats obsessionades amb el passat» (2016, p. 28). Vindria a ser la mateixa línia argumental de Dubravka Ugrešić, que ha practicat aquesta tecnologia de la memòria, l'àlbum i l'autobiografia, mitjançant la integració sabeldiana de text i fotografia, «activitats guiades per l'àngel de la nostàlgia», guionista de la vida, capaç d'organitzar el relat, el sentit, a partir dels fragments d'aquesta memòria (Ugrešić, 1996, p. 57). Seguint el parell de límits establert per Koselleck, Traverso afirma que l'horitzó d'expectativa que havia proporcionat la utopia comunista hauria desaparegut, i que l'espai d'experiència que havia permès assajar aqueIla fórmula utòpica hauria mutat en un «camp de ruïnes». No hi ha a la vista cap horitzó d'expectativa: «la utopia sembla una categoria del passat»; i afegeix: «la història mateixa es presenta com un camp de ruïnes» (Traverso, 2016, p. 34). Un escenari propici per a la tragèdia.

Per tant, més que un final de la història, s'hauria assistit a un reciclatge del que significa la història i el fet històric, transmutat en clau de memòria col-lectiva, com a símptoma del presentisme de la societat actual. A l'espera de noves utopies, s'imposa el present com a única realitat, «un temps suspès entre un passat indomtable i un futur negat» (Traverso, 2016, p. 35). Per aquesta raó, l'eclipsi de les utopies origina una mirada al passat situant la víctima, «una figura abans discreta i modesta», al centre de l'univers històric, mutat cap a allò memorístic: «L'empatia amb les víctimes il-lumina el segle XX amb una nova llum» (Traverso, 2016, p. 38), unes víctimes que ens vindran a recordar constantment que són el fruit de la utopia i representants d'aquestes ruïnes contemplades per l'àngel de la història de Benjamin.

Així doncs, el gir que es produeix el 1989 és conseqüència del «xoc entre la història i la memòria» (Traverso, 2016, p. 39), un xoc que dona la victòria, fins ara provisional, a la segona, una memòria percebuda com al.legat a no repetir els errors d'aquest món, més que a la mobilització per transformar-lo: una memòria anestèsica. Després de 1989, ja no funciona la cultura del dol perquè s'instal-la la sensació que la caiguda del Mur és irreparable i que només queda una única via: «Como las utopías han llegado a su fin, un duelo logrado podría significar asimismo la identificación con el enemigo: el reemplazo del socialismo perdido por el capitalismo aceptado.» (Traverso, 2016, p. 96).

Efectivament, el socialisme havia estat percebut com un moviment alliberador, i no com un enfrontament violent portador de mals per a la humanitat; era una proposta redemptora que vindria a resoldre les limitacions humanes, en clau moral i material: «Com a visió teleològica de la història, el socialisme no admetia la tragèdia», afirma Traverso 
(2016, p. 108). Aquell relat utòpic havia sorgit de l'optimisme que suposa dipositar la confiança en la convicció forta que el gènere humà és capaç d'avançar cap a un món just i harmònic que tanqui les ferides de la història, i que fins i tot arribi a tancar la història mateixa. Una utopia que venia a aplegar aquells dos vectors que la modernitat i el capitalisme industrial, empesos pels perills del progrés i l'emancipació (Taguieff, 2001, 2019), haurien instal.lat en l'imaginari del subjecte encara utòpic: l'esperança i la responsabilitat.

\section{Heroïcitat tràgica i error pedagògic}

En aquesta tessitura, podria semblar pelegrí situar la utopia al costat de la tragèdia, quan en realitat dominaria, en l'imaginari col-lectiu, una oposició sòlida que ressegueix la que va establir Nietzsche entre l'optimisme teòric i el pessimisme pràctic en El naixement de la tragèdia, tot i que segons el parer de Kaufmann, «Nietzsche ens va perjudicar molt quan, en la seva joventut, sota la influència de Schopenhauer, va introduir aquests termes parlant de la tragèdia». Segons la seva opinió, «optimisme i pessimisme són categories simplistes.» (Kaufmann, 1968, p. 281).

En el seu sentit clàssic, doncs, la tragèdia refereix les gestes d'un heroi embolicat en la glòria que assolirà més relleu gràcies al contrast que sorgeix del «fons fosc» d'una mort, assumida com a inevitable i previsible, que el conduirà cap a un «llòbrec món d'ombres no millor que el no res absolut» de l'home corrent (Lesky, 1958, p. 33). Allò tràgic «depassa els límits del que és normal», en un sentit d'ampul-lositat i solemnitat, però s'ajusta als límits del que és esperable.

Com expressa Di Giacomo, seguint al Lukács jove, l'obra d'art neix de «la consciència de la necessitat del límit, és a dir del no-sentit, i per això la tragèdia no és negació de l'ésser finit, sinó "saviesa dels límits", "vivència del límit".» (Di Giacomo, 1999, p. 53). L'heroi tràgic es mou per motivacions elevades, dictades pel destí, molt per sobre o potser al marge de les normes de la vida quotidiana. L'heroi tràgic ho és en la mesura que arriba a reconèixer la seva culpa, que no és una falta moral sinó epistemològica (Lesky, 1958; Kaufmann, 1968).

En altres paraules, la falta de l'heroi tràgic és un error de comprensió del sentit últim, i d'aquí la veritable tragèdia: si ho hagués sabut es podria haver evitat, com en el cas de I'infeliç Èdip, segons l'exemple que utilitza Kaufmann. La consideració moral de la caiguda o falta tràgica vindrà amb Sèneca i es consolidarà amb el cristianisme, segons Lesky, per a qui aquesta caiguda es produeix des d'un «món il-lusori de seguretat i felicitat a les profunditats d'una misèria ineludible» (Lesky, 1958, p. 45). No interessa ara aprofundir en aquesta característica, però és interessant ressaltar com l'heroi tràgic, al menys el grec clàssic i l'isabelí shakespearià, es mourà en aquesta actitud sempre ambivalent i contradictòria que implica la conservació de la dignitat, un traç tràgic per excel.lència, amb la rauxa passional derivada de l'anagnòrisi, un altre element de la tragèdia. En clau d'utopia, el símil es troba en la tensió que sorgeix de mantenir l'equilibri entre els dos mons, el conegut i l'augurat, l'interior i l'exterior, una tensió que l'utopista postmodern experimentarà $a m b$ inquietud, fins i tot amb temor.

Si la tragèdia permetria donar per acabat el projecte humà, la utopia s'instal-lava en aquest final imperfecte de la història. D'aquesta manera es pot entendre la dificultat hermenèutica que planteja el disseny utòpic per ser encaixat en un marc ètic de millora i perfectibilitat de l'ésser humà i la societat. Encara sostenint que aquesta pogués ser la 
intenció artística, podria considerar-se la utopia com l'intent per construir un relat estructurant i tràgic. Des de la seva posició crítica amb la realitat, la utopia s'ocupa d'una funció totalitzadora, de proporcionar un sentit absolut i orientar l'acció, com a marc cognitiu ampli (Navajas, 2008, p. 137), i versàtil per adaptar-se a la naturalesa líquida de la modernitat tardana. Aquesta funció podrà ser reeixida en la mesura que el relat utòpic se separi d'una voluntat absoluta i modèlica, una circumstància que aniria més enllà de les seves funcions (Navajas, 2008, p. 138). La mateixa condició d'impossibilitat de la utopia li proporciona la seva força ja que, a l'igual que la ficció (Catelli, 2017), la utopia no requereix ser verificada.

En la confluència de tres autors es troba el fonament d'aquesta hipòtesi, segons Navajas: la provisionalitat del pensament (il pensiero debole) de Vattimo; la minimització de les idees de Lipovetsky, i la microhistòria de Lyotard. L'origen es podria rescatar de Hegel i la seva descripció de la consciència o l'ànima desgraciada de la primera modernitat, necessitada de motivacions de sublimació a causa de la constatació de la tragèdia de la finitud: nació, estat, mercat, cosmos, ciència. Nocions, totes elles, que han alimentat utopies en els dos últims segles, i desemmascarades pels fets i per les distopies corresponents. En aquest sentit, el modernisme literari europeu, segons el parer de Navajas, seria incompatible amb la hipòtesi estructurant dels models utòpics que acaben negant el subjecte, un jo personal que Freud intentaria rescatar des de la psicoanàlisi. Apareix la contrautopia, per contrarestar els efectes perversos dels relats totalitzadors utòpics. Emergeix una literatura que reclamarà el protagonisme d'un jo personal modernament tràgic (Proust, Woolf, Musil, Huxley).

\section{Reiteració i menuderies}

El text literari, per tant, se situa en el punt de tensió que sorgeix entre el món de la vida i el món de la forma. L'intent de donar forma a la vida real, o de trobar un sentit ètic al món des del projecte artístic, pretensió d'algun corrent estètic, com el Romanticisme, està condemnat al fracàs. La diferència entre el Romanticisme de Goethe i el d'altres, com el de Novalis, apunta Lukács, segons Di Giacomo, és que el primer se situa a la vida mateixa per sostenir el seu projecte estètic, mentre que els segons confonen art i vida. No es tracta, per tant, d'eliminar la distància entre vida i art, o entre ètica i estètica; com tampoc es tracta d'involucrar l'art en l'ètica o de mesurar-lo a partir de paràmetres morals, segons Lukács. Precisament, la possibilitat de la cultura per Lukács se sosté des del reconeixement de la «realitat històrica del passat (grecitat)» però també com «utopia indefinida projectada en el futur», explica Di Giacomo (1999, p. 47). I afegeix:

La tragedia es para Lukács la máxima expresión de la esencia y de aquella forma en la cual él veía la condición misma del verdadero arte. La forma trágica es el medio a través del cual la relatividad de la existencia cotidiana es definitivamente superada y el hombre vive de manera plenamente consciente la propia finitud. (Di Giacomo, 1999, p. 53)

La tragèdia del subjecte modern serà el reconeixement concloent de la finitud davant un món que es presentava infinit, seguint els postulats emancipadors de tarannà optimista. Un avançament literari el proporcionaria la tragèdia del Frankenstein de Mary Shelley, on l'aventura prometeica queda avortada quan Víctor Frankenstein es nega a atorgar un horitzó d'esperança a la seva criatura quan li reclama una companya per a la seva posterior supervivència: la ciència li ho negarà no perquè s'albiri l'horror mateix de crear una criatura deforme, èticament i estèticament, sinó perquè s'endevina l'horror d'un món fora de control de la ciència mateixa, més enllà dels límits coneguts. Tot i el seu impuls 
utòpic, en la ciència, l'arquitectura o el desenvolupament moral, el subjecte modern és intrínsecament tràgic. Per a alguns autors, aquesta tradició de tall tràgic es va trencar amb el capitalisme tardà (Fisher, 2009) i els postmodernismes artístics (Jameson, 1991).

Fisher argumenta que el capitalisme tardà no aporta més novetat que la reiteració i la barateria de les menuderies. El seu poder rau en la capacitat de «assignar valor monetari a tots els objectes culturals, no importa si parlem de la iconografia religiosa, de la pornografia o de El Capital de Marx» (Fisher, 2009, p. 25). En aquest procés, el passat admet fàcilment aquesta monetarització, quan es converteix la tradició en revival o pastitxos, en objectes la significació històrica de la qual queda anul·lada: «el modernisme en veritat s'ha convertit en una cosa que pot tornar periòdicament com un estil estètic congelat encara que no ja com un ideal de vida.» (Fisher, 2009, p. 30). El capitalisme, segons el parer de Fisher, arriba a ocupar totes les facetes del subjecte, «tot allò pensable», fins i tot la seva vida onírica: «el capital persegueix el subjecte fins quan està dormint» (Fisher, 2009, p. 65). El seu objectiu, clarament assolit, és el de «eradicar la categoria de valor en un sentit ètic», és a dir, de relativitzar i consentir tot el que no posi en qüestió la idea del mercat en constant expansió, aquesta idea del creixement infinit, mitjançant una estratègia hàbil de «lassitud hedònica». Posa l'exemple d'adolescents als que la lectura els resulta avorrida, un acte que els priva de la seva connectivitat a un món virtual, un matrix que proporciona plaers reiteratius, un «consum narcòtic que posa un mur entre el subjecte i l'esfera social» (2009, p. 52-53) i condueix a la desmobilització col-lectiva. En aquesta estratègia, «el temps deixa de ser lineal i es torna caòtic», esmicolat en unitats mínimes, el que evidentment complica la seva comprensió i la configuració de sentit. Segons Fisher, només quan el subjecte és capaç de reconèixer les causes veritables de les seves accions, quan pot deixar enrere les «passions tristes» que l'intoxiquen, està en condicions d'aconseguir la llibertat. Una anagnòrisi certament tràgica, que la postmodernitat ha sabut edulcorar anteposant el sentir al pensar: «el sentiment va reemplaçar la moralitat» (Fisher, 2009, p. 113), i allò emocional va inundar la racionalitat, en una jugada certament democràtica ja que tothom té emocions, però no està demostrat, per al postmodern, que tothom raoni.

S'intueix, per tant, que aquest procés d'enfonsament dels relats forts i d'atomització o desmembrament del sentit no permet una crítica estilística o moralista, pròpia de la modernitat, sinó que el caràcter històric de la postmodernitat, «com a pauta cultural dominant de la lògica del capitalisme tardà» (Jameson, 1991, p. 66), exigeix una crítica política, l'expressió que reclamava Fisher. En termes epistemològics, la postmodernitat hauria imposat una manera sincrònica de pensar, superadora de la història, on no s'admet comparació ja que la irreductibilitat moral impedeix tot contrast. Davant d'aquesta exigència d'allò sincrònic, Jameson anteposa la condició genuïna del diacrònic, el «pensar», malgrat les seves deficiències (Jameson, 1991, p. 155). Per al crític cultural, caldria descartar la possibilitat de la utopia ja que la dominant cultural ho impedeix i es podria orientar la producció cap al reaprofitament i el reciclatge, característiques intrínseques de la utopia distòpica contemporània.

La postmodernidad ya no produce obras monumentales del tipo moderno sino que reorganiza sin cesar los fragmentos de textos preexistentes, los bloques de construcción de la antigua producción cultural y social, en un bricolaje nuevo y dignificado: metalibros que canibalizan a otros libros, metatextos que recopilan trozos de otros textos. (Jameson, 1991, p. 125) 


\section{Catarsi i tragèdia pedagògica}

Tot això condueix a la funció catàrtica en què coincideixen utopia i tragèdia, ja recollida per Aristòtil, al menys en el format teatral que va dibuixar en la Poètica, com a art «representat i no narrat», que activa les passions i els temors de l'espectador, desencadenant simpaties i rebutjos. Com va quedar indicat a propòsit de la falta comesa per l'heroi tràgic, aquesta funció purgant no seria tant d'ordre moral com epistemològica i, per tant, de caràcter pedagògic, de creixement personal. Per Kaufmann, la catarsi tràgica conduiria no tant a una aflicció per part de l'espectador, que potser pogués produir-se en persones summament sensibles, sinó a un alleujament pels mals que aguaiten a un altre, a l'heroi, operant a manera d'avís, en aquest cas pel seu error epistemològic: un desconeixement que el subjecte post-il.lustrat ja no podrà al.legar.

La catarsi tràgica, igual que algunes distopies, vindria a ser una mena de bàlsam, un autèntic alliberament, a conseqüència d'aquesta predicció davant la qual queden poques opcions, per no dir-ne cap, cosa que requerirà de la preparació de l'heroi, a més de la de l'espectador. És el que Goethe expressarà al canceller Von Müller, segons recull Lesky: «Tot el tràgic es basa en un contrast que no permet cap sortida. Tan aviat com la sortida apareix o es fa possible, la tragèdia s'esfuma» (Lesky, 1958, p. 42). Aquest contrast, per Kaufmann, resseguint a Sòfocles, serà sempre entre el bo i el bo: «El fet essencialment tràgic és la autodivisió i el combat intern de la substància ètica, no tant la guerra del bo amb el dolent, com la guerra del que és bo amb el bo» (Kaufmann, 1968, p. 313). Una tensió dialèctica que increpa un subjecte post-utòpic, potser un lector emancipat (Rancière, 2008), el que ha conegut l'ocàs de les utopies i ha reconegut el deliri de les distopies.

Podria plantejar-se, per tant, que allò que posa en un mateix pla tragèdia i utopia seria la voluntat dels dos projectes de discórrer per un relat estructurant, totalitzador, catàrtic, que proporcioni sentit al món de la vida. En certa mesura, són relats finalistes, que no ofereixen possibilitat de continuació: res no hi ha més enllà de la tragèdia; no és possible pensar un món després de la utopia, sigui positiva («cim de l'esperança humana») com a negativa («no hi ha salvació possible»). En el cas de la tragèdia, l'espectador sabrà que no hi ha solució possible per a l'heroi més que en la seva desgràcia, sigui en el desenllaç (autòlisi, auto-enucleació, suïcidi, assassinat) sigui en alguna de les peripècies que esdevenen en la trama, quan l'heroi arriba a una anagnòrisi fatalista, en absolut agradable per al món que s'havia creat.

A la utopia, el lector esperaria alguna cosa diferent, però el seu desenllaç pot deixar un sabor amarg quan es constata la pèrdua de la condició individual a favor del grup, quan l'èxit de la proposta utòpica depèn invariablement de la disposició del subjecte a subjugar-se a la felicitat col-lectiva. Però encara és més tràgic, per al utòpic, haver d'admetre que l'única utopia factible és la que reclamava Wells (1905), que Le Guin també relata i que teoritzava Fernández Buey (2007): la utopia imperfecta, l'efecte tràgic de la qual rau precisament a reconèixer que la utopia és dinàmica i ja no és finalista o, en el pitjor dels casos, la que obliga a redescobrir que la utopia és simple elucubració.

El subjecte que es vol post-utòpic es mou en la tensió que genera la il.lusió de pensar un món millor i d'allunyar-se'n per no prendre-hi mal; dos pols separats per un mur infranquejable que, en el camp de l'art, es tradueix en una «oscil|lació entre voler l'autonomia i no poder transcendir-la» (García Canclini, 2010, p. 17). Entre emancipació i impotència, l'art, en paraules de García Canclini, ha desplaçat «les pràctiques artístiques basades 
en objectes a pràctiques basades en contextos», que arriben a formar part dels canals digitals de difusió, en un exercici d'integració advertit per Eco en la dècada de 1960. En aquesta integració, l'art perd quotes d'autonomia i esdevé post-autònom, potser més per indiferència que per conveniència. Si la condició epistèmica de la utopia era la imaginació, que mitjançant la mimesi mostrava la possibilitat d'altres mons des de la coherència, I'harmonia i la unitat de sentit que donaria l'art, la postmodernitat vindria a desmuntar aquest prejudici trencant l'encadenament causal (el no sentit, o la manca de sentit), erosionant el llenguatge i la versemblança, i imposant la fragmentació. El pas cap al nihilisme estaria servit.

Aquest subjecte que es vol post-utòpic ve a qüestionar el fonament de la modernitat, aquell triangle que proporcionava les seguretats del món d'ahir: un projecte poètic, un programa humanista i una voluntat pedagògica. El primer venia a proposar una ficció on s'albirava un altre món sempre millor; el segon traçava un esquema d'elements materials i simbòlics que establien les relacions socials i polítiques d'aquell món, fins al present en clau humanista, i amb la postmodernitat, en altres claus; i el tercer venia a narrar els obstacles i les fortaleses que explicarien la possibilitat d'aquest horitzó desitjable, marcant una tensió en el subjecte, i reflectida en la novel.la de formació, entre autodeterminació i socialització (Moretti, 1985, p. 115). Amb la caiguda de les utopies, probablement ja no funcioni aquesta equació.

Els avisos de la fi de la utopia s'havien intensificat quan Bloch i Marcuse van llançar els seus missatges com a rèplica a Popper i Berlin. La revolució neoconservadora de dues dècades més tard, la de 1980, trencava gairebé definitivament amb la possibilitat de la utopia. Apocalypse Now (1979, de Francis F. Coppola), i els fenòmens derivats de Blade Runner (1982, Ridley Scott), Mad Max (1979, George Miller), i tot un reciclatge cinematogràfic de textos literaris que havien servit d'admonició d'aquest final anunciat, esdevenien emblemes d'un canvi d'època. Just al final d'aquella dècada, la caiguda del Mur suposava la pèrdua material i simbòlica d'un relat social que havia confiat en utopies, d'unes narratives que aportaven redempció i salvació al subjecte i a la comunitat, de manera que I'horitzó es va fragmentar en tantes possibilitats com reivindicacions: el relat que podria sorgir a partir d'aquí hauria de recollir aquests fragments i només seria possible gràcies a ells. Una mica més tard, el món després de la crisi financera de 2008 obligaria a recuperar refugis i aixoplucs construïts des del reciclatge per protegir-se d'unes inclemències vaticinades per relats que començaven a mostrar aquests signes de vida post-utòpica. Els efectes paradoxals de la pandèmia de 2020, encara per descobrir, es fan notar en un increment de l'aïllament social i de la connectivitat virtual, una ambivalència provocada per una fugida subtil del nihilisme per part de subjectes que no esperen res de les utopies però que anhelen alguna cosa més: si les utopies havien col-lapsat amb els relats de la modernitat, els horitzons dissenyats pels postmodernismes no haurien convençut més que als seus devots.

El subjecte post-utòpic assumeix que la seva seguretat consisteix precisament en convertir la seva fragilitat en fortalesa, «de ser sotmès, de tornar al mite, a través de l'adopció d'una llei arbitrària -sovint religiosa- capaç de sostreure's del seu buit d'autoritat» (Villanueva Mir, 2008, p. 511). Potser ha reconegut el seu esgotament, com Europa, cansada de «guerres, ideologies i utopies» (Ugrešić, 2005, p. 113). El triangle irregular que s'ha anat formant amb el nihilisme, el reciclatge i la fragmentació, com a línies discontínues que anirien dibuixant una gramàtica per a temps posteriors a la utopia, es completa 
o, més aviat, adquireix moviment, amb la perspectiva que aporta l'efecte tràgic. La tragèdia sempre ha tingut un elevat grau d'atracció, a l'igual que la distopia: «en la fascinació per la distopia batega el fons escatològic de la psique humana» (Arias Maldonado, 2018). El seu alt poder seductor vindria a satisfer aquella necessitat d'alleujament catàrtic que Aristòtil atribuiia a la provocació dels terrors i al despertar de la sensibilitat humana. Però el subjecte post-utòpic sembla vacunat davant d'aquests estímuls. Més aviat sembla que la distopia no li ofereix més satisfacció que les comèdies romàntiques o els relats d'aventures, transmutats ara cap a civilitzacions ahistòriques i atòpiques, com Jocs de la fam o Joc de trons, relats curiosament encapçalats per aquesta referència lúdica, reclam de distracció i rebuig de l'avorriment.

Com no podia ser d'una altra manera, el subjecte post-utòpic es troba en una tensió tràgica que l'obliga a reconèixer el benefici personal que li ha suposat l'avenç científic i tecnològic, alhora que s'atreveix a amagar els seus efectes col-laterals, en clau de desigualtat, escassetat o fragilitat sistèmica d'un planeta en deteriorament aparent. I potser per aquesta raó, també estaria en condicions de separar aquest progrés material del progrés moral, del qual vindria a esperar més aviat poc. En aquest context, el relat utòpic tampoc podria ser moralista. En el pitjor dels casos, el subjecte post-utòpic seria capaç d'albirar que la utopia i la tragèdia són les dues cares d'una mateixa trampa. La societat del risc i la responsabilitat hauria estat reemplaçada per la societat del fracàs i l'esperança. I és que potser la utopia, des del seu inici, ja portava incorporada la llavor de la tragèdia

\section{Referències}

Arias Maldonado, Manuel (2018) «Utopía sin utopía». Revista de Libros, 13.6.2018. Disponible a https://www.revistadelibros.com/blogs/torre-de-marfil/utopia-sinutopia (Consulta 22.2.2020).

Bloch, Ernst (1980) Despedida de la utopía. Madrid, Antonio Machado Ed., 2017 (Trad. Sandra Santana Pérez).

Bloch, Ernst (1993) «Ontología del "aún-no"». Anthropos: Boletín de información y documentación, Extra 41, p. 8-21.

Catelli, Nora (2017) «Posverdad y ficción», a Jordi Ibáñez Fanés (Ed.) En la era de la posverdad. Barcelona, Calambur Ed., p. 139-146.

Di Giacomo, Giuseppe (1999) Estética y literatura. La gran novela entre el Ochocientos y el Novecientos. València, Publicacions de la Universitat de València, 2014 (Trad. Diego Malquori).

Drndič, Daša (2007) Trieste. Madrid, Automática Editorial, 2015 (Título original: Sonnenschein. Trad. Simona Škrabec).

Fernández Buey, Francisco (2007) Utopías e ilusiones naturales. Barcelona, Ediciones de Intervención Cultural / El Viejo Topo.

Fisher, Mark (2009) Realismo capitalista. ¿No hay alternativa? Buenos Aires, Caja Negra Editora, 2016 (Trad. Claudio Iglesias).

García Canclini, Néstor (2020) La sociedad sin relato. Madrid, Katz.

Jameson, Fredric (1991) Teoría de la postmodernidad. Madrid, Trotta, 2016 (Trad. Celia Montolío Nicholson y Ramón del Castillo).

Kaufmann, Walter (1968) Tragedia y filosofía. Barcelona, Seix Barral, 1978 (Trad. Salvador Oliva).

Lesky, Albin (1958) La tragedia griega. Barcelona, Acantilado, 2001 (Trad. Juan Godó). 
Lukács, György (1920) Teoría de la novela. Barcelona, Penguin Random House, 2016 (Trad. Manuel Sacristán).

Magris, Claudio (1996) Utopía y desencanto. Barcelona, Anagrama (Trad. José Ángel González Sainz).

Magris, Claudio (2007) «ll bugliardo che dice la verità». Corriere della Sera, 21 gener 2007. Magris, Claudio (2015) Non luogo a procedere. Milán, Garzanti.

Moretti, Franco (1985) «The Comfort of Civilization». Representations, 12, p. 115-139. Consulta a https://www.jstor.org/stable/3043781 (22.2.2020).

Navajas, Gonzalo (2008) La utopía en las narrativas contemporáneas. Saragossa, Prensas Universitarias de Zaragoza.

Rancière, Jacques (2008) El espectador emancipado. Castellón, Ellago, 2010 (Trad. Ariel Dilon; rev. Javier Bassas Vila).

Serés, Guillermo (2019) Historia del alma. Antigüedad, Edad Media, Siglo de Oro. Barcelona, Galaxia Gutenberg.

Taguieff, Pierre-André (2001) Du progrès. Biographie d'une utopie moderne. París, Librio

Taguieff, Pierre-André (2019) L'émancipation promise. Exigence forte ou illusion durable? Paris, Editions du Cerf.

Traverso, Enzo (2016) Melancolía de izquierda. Después de las utopías. Barcelona, Galaxia Gutenberg, 2019. (Trad. Horacio Pons).

Trousson, Raymond (1979) Historia de la literatura utópica. Viajes a países inexistentes. Barcelona, Península, 1995 (Trad. Carlos Manzano).

Ugrešić, Dubravka (1996) El Museo de la Rendición Incondicional. Barcelona, Alfaguara, 2003 (Trad. M. Ángeles Alonso i Dragana Bajic).

Ugrešić, Dubravka (2005) No hay nadie en casa. Barcelona, Anagrama, 2009 (Trad. Luisa Fernanda Garrido Ramos i Tihomir Pištelek).

Villanueva Mir, Marc (2018) «De la isla a la frontera. La problematización del espacio en la ficción distópica contemporánea». Tropelías. Revista de Teoría de la Literatura y Literatura Comparada, 29, p. 506-521.

Wells, Herbert George (1905) Una utopía moderna. México DF, Océano, 2000 (Trad. Jorge A. Sánchez Rottner). 


\section{La utopía como tragedia moderna de los sujetos post-utópicos}

Resumen: El sentido común situaría los términos utopía y tragedia en polos semánticos opuestos En el terreno del pensamiento pedagógico, desde hace dos siglos, la educación se habría situado más bien en el primero de estos extremos, salvo algunas destacadas excepciones. Muy probablemente la embestida moderna, con ideas tan seductoras como las de progreso y emancipación, habría conducido aquellas pedagogías por territorios curtidos por el optimismo y la expectativa de mundos mejores, siempre de la mano de la educación como herramienta para alcanzarlos. También muy probablemente, en cambio, el hundimiento de las utopías totalizantes durante el siglo xx habría sido el síntoma de un mal endémico todavía por averiguar. La tragedia de la finitud, escondida con la modernidad, quedaría al descubierto con aquel desplome, una situación que los post-modernismos hubieran querido superar con la negación de la historia y, también, del futuro. El sujeto post-utópico emerge como alguien que no espera más que un futuro programado que no despierta ningún tipo de pasión, una verdadera tragedia para la pedagogía.

Palabras clave: Postmodenrindad, utopía, tragedia, pedagogía.

\section{L'utopie en tant que tragédie moderne des sujets post-utopiques}

Résumé: Le sens commun situerait les termes « utopie » et " tragédie » sur des pôles sémantiques opposés. Dans le champ de la pensée pédagogique, depuis deux siècles, l'éducation se serait plutôt située à la première de ces extrémités, à part quelques rares exceptions. Très probablement, l'offensive moderne, avec des idées aussi séductrices que celles de progrès et d'émancipation, aurait conduit ces pédagogies dans des territoires plongés dans l'optimisme et l'attente de mondes meilleurs, s'appuyant toujours sur l'éducation en tant qu'outil permettant de les atteindre. En revanche, très probablement aussi, l'échec des utopies totalisantes au cours du xxe siècle aurait été le symptôme d'un mal endémique encore à découvrir. La tragédie de la finitude, cachée par la modernité, serait mise à nu avec cet accroupissement, une situation que les postmodernismes auraient voulu dépasser avec la négation de l'histoire et, aussi, de l'avenir. Le sujet post-utopique émerge comme quelqu'un qui n'attend rien d'autre qu'un avenir programmé n'éveillant aucun type de passion, une véritable tragédie pour la pédagogie.

Mots-clés: Postmodernité, utopie, tragédie, pédagogie.

\section{Utopia as a modern tragedy of post-utopian subjects}

Abstract: Common sense would place the terms utopia and tragedy at opposite semantic poles. In the field of pedagogical thought, for the past two centuries, education would have been at the first of these extremes, with a few notable exceptions. Most likely the onslaught of seductive modern ideas like those of progress and emancipation, would have led those pedagogies through territories fertilized by optimism and the expectation of better worlds, always with education as a tool for achieving. However, it is also very likely that the collapse of totalizing utopias during the twentieth century was the symptom of an endemic disease yet to be found. The tragedy of finitude, hidden within modernity, would be exposed with this, a situation that post-modernisms wanted to overcome with the denial of history and, also, of the future. The post-utopian subject emerges as someone who expects nothing more than a programmed future that awakens no passion at all, a real tragedy for pedagogy.

Keywords: Postmodernity, utopia, tragedy, pedagogy. 